\title{
La centralización de la educación pública primaria en el Perú y sus consecuencias tempranas, 1905 a 1921
}

\section{The centralization of the public elementary school in Peru and its early consequences, 1905-1921}

G. ANTONIO ESPINOZA

Virginia Commonwealth University

gaespinoza@vcu.edu

\section{RESUMEN}

En 1905, el Segundo Civilismo centralizó la administración y financiamiento de las escuelas públicas primarias, asi como también el nombramiento y fiscalización de los maestros. Los factores ideológicos que motivaron al régimen de José Pardo a tomar dicha medida incluyeron el nacionalismo y el positivismo, mientras que una de sus motivaciones politicas fue afianzar su poder al interior del civilismo y por encima de los poderes locales. Entre las circunstancias que favorecieron la centralización, estuvieron la disponibilidad de recursos fiscales y el apoyo de parte del magisterio. Las consecuencias de la medida incluyeron el incremento del número de escuelas y alumnos matriculados, el aumento en el número de docentes (especialmente mujeres), la intensificación de la renovación pedagógica, y la consolidación de una nueva cultura magisterial.

Palabras clave: Educación, centralización, Segundo Civilismo, magisterio, Escuela Normal de Varones de Lima 


\section{ABSTRACT}

In 1905, the Second Civilismo centralized the administration and financing of public elementary schools, as well as the appointment and supervision of teachers. The ideological factors that motivated José Pardo's regime to take such action included nationalism and positivism, while one of its political motivations was to consolidate its power within Civilismo and over local powerholders. Among the circumstances that favored centralization were the availability of fiscal resources, and the support from some teachers. The consequences of the measure included an increase in the number of schools, growing enrollment, a growing number of teachers (especially women teachers), , the intensification of pedagogical renewal, and the consolidation of a new schoolteachers' culture. Keywords: Education, centralization, Second Civilismo, schoolteachers, Men Teachers School of Lima

$\mathrm{L}$ a existencia de un sistema centralizado de educación pública primaria omite que hasta 1905 la administración y financiamiento de las escuelas estaba en manos de las autoridades municipales. En este artículo, se analizan algunos de los factores ideológicos y políticos que motivaron a las autoridades nacionales a centralizar la instrucción primaria mediante la ley número 162, de 1905, así como también las circunstancias institucionales y financieras que favorecieron dicha reforma. Se plantea que entre los factores que incentivaron al gobierno central estuvieron el nacionalismo y el positivismo, y el afán de la facción gobernante del Partido Civil por afirmar su poder. Con respecto a las condiciones favorables a la centralización, entre ellas estuvieron la relativa holgura fiscal y el apoyo de cuando menos parte de los docentes.

Asimismo, se examinan las consecuencias de la centralización para la escolaridad y el magisterio en el corto y mediano plazos. Los efectos decididamente positivos de la reforma fueron el incremento del total de escuelas y de alumnos matriculados, la expansión del magisterio y una mayor participación de las mujeres en el mismo, y la intensificación de la renovación pedagógica. Sin embargo, luego de la reforma, los docentes 
no alcanzaron las condiciones materiales y profesionales que esperaban. Uno de los factores fue, por ejemplo, que los poderes locales cuestionaron a los inspectores escolares dependientes del gobierno central hasta lograr su abolición temporal. Frente a estas dificultades que afrontaban, los maestros recurrieron a estrategias como el asociacionismo, las reuniones profesionales y las publicaciones especializadas, con la finalidad de afirmarse como especialistas educativos, comunicar sus necesidades y expectativas a las autoridades, y crear relaciones de solidaridad. Ya a principios del Oncenio de Leguía (1919-1930), la Ley Orgánica de Enseñanza de 1920 ratificó la centralización de la educación pública primaria.

Los cambios educativos introducidos en el Perú a principios del siglo XX no fueron exclusivos de nuestro país. En el caso europeo, Margaret Archer ha analizado el surgimiento de sistemas educativos estatales entre mediados del siglo XIX y principios del XX. Los define como un conjunto de instituciones educativas diferenciadas, de alcance nacional, cuyo control y supervisión estaban al menos parcialmente en manos del gobierno, y cuyos componentes y procesos estaban relacionados entre sí. En los Estados Unidos, los gobiernos estatales y locales establecieron sistemas educativos desde la segunda mitad del siglo XIX. Según Michael Katz, se caracterizaron por articular jerárquicamente escuelas con grados clasificados por edades, y que eran en su mayoría gratuitas y obligatorias. La administración de dichas escuelas estaba a cargo de expertos a tiempo completo y, progresivamente, los docentes recibían una capacitación específica para la enseńanza. En el caso de América Latina, Carlos Newland sostiene que, desde principios del siglo XX, los gobiernos de los países de la región adoptaron el modelo de Estado docente, definido como un marco institucional relativamente centralizado, con facultad para proporcionar servicios educativos y definir contenidos curriculares. Newland considera que los factores que permitieron su gradual establecimiento fueron la disponibilidad de recursos, la urbanización, y la influencia del positivismo y del nacionalismo. ${ }^{1}$

1 Archer 2013: 54; Katz 1987: 6; Newland 1994. 


\section{LA CENTRALIZACIÓN}

En el caso peruano, el nacionalismo y el positivismo también alentaron el establecimiento del Estado docente. Luego de la derrota en la Guerra del Pacífico (1879-1883), fomentar la lealtad a la comunidad nacional imaginada pasó a ser un tema prioritario para las élites. Tanto políticos como intelectuales consideraron a la educación como un instrumento ideal para cohesionar a la población frente a las amenazas externas y las divisiones internas. Durante y después de la guerra, charlas, ensayos, programas de estudio, libros de texto, y actividades escolares promovieron un nacionalismo abarcador, militarista, y revanchista, mas no igualitario, y, por tanto, solo relativamente democrático. ${ }^{2}$ El positivismo incidía también en la necesidad de fortalecer la identificación con la nación y la lealtad hacia ella. ${ }^{3}$

Jorge Polar Vargas, filósofo positivista y ministro de Instrucción (19041906) cuando se introdujo la centralización, era un defensor de la realidad natural, moral, y jurídica de la patria peruana. Sostenía que los peruanos estaban unidos por un territorio que habían heredado, por los recuerdos asociados a dicho territorio, por antepasados comunes, y por una historia compartida. Por todo ello, decía, le debían un amor celoso y exclusivo, y disposición al servicio y al sacrificio, además de sus obligaciones legales. ${ }^{4}$ Manuel Vicente Villarán, también filósofo positivista y ministro de Instrucción (1908-1909), fue uno de los más firmes defensores de la centralización. En una serie de artículos acerca de la instrucción primaria en el Perú republicano, criticó los defectos de la descentralización. Implícitamente, Villarán presentaba el paso a una organización centralizada como una evolución necesaria hacia el progreso. ${ }^{5}$

Entre los defectos de la organización descentralizada mencionados por Villarán, se encontraban: la insuficiencia de los recursos destinados a la instrucción por los gobiernos locales; la falta de dedicación y preparación

2 Espinoza 2013: 69-75, 148-152. Contreras también relativiza la «inclusividad» del proyecto educativo del Segundo Civilismo (1996: 6-9).

3 Eastwood 2004.

4 Polar 1900: 173-182.

5 Villarán 1913: 313-323, 547-561; Villarán 1914: 201-223. 
de los funcionarios departamentales, provinciales, y distritales para supervisar las escuelas; y la ausencia de vigilancia del gobierno central. Asimismo, la carencia de una entidad directora central y de un cuerpo de inspectores profesionales. ${ }^{6}$ Si bien las críticas de Villarán eran fundadas, pasó por alto que las escuelas existentes proporcionaban una base material y magisterial para las iniciativas emprendidas por José Pardo. Más allá de sus deficiencias, en 1905, antes de la centralización, había 1425 escuelas públicas, con un total de 1657 docentes y 85000 estudiantes. ${ }^{7}$ Con la ley número 162, el gobierno nacional asumió el control de dichas escuelas y absorbió los recursos manejados hasta entonces por los municipios, incrementando el monto total destinado a la instrucción primaria. El fondo para dicho ramo quedó conformado por el mojonazgo municipal (impuesto sobre el consumo de algunos alimentos, licores, y hojas de coca), los impuestos y bienes locales ya destinados a las escuelas, el 35 $\%$ de las rentas de las juntas departamentales, y el $5 \%$ de los ingresos fiscales. La ley preveía que, si el mojonazgo excedía el $50 \%$ de los ingresos totales de un municipio, las autoridades nacionales reintegrarían la diferencia con respecto a dicho monto. En cuanto a las rentas departamentales, en 1904 solo 7 de 19 departamentos invirtieron 30 $\%$ o más de su presupuesto en instrucción primaria. Hasta entonces, el porcentaje presupuestario más alto invertido por el gobierno central en la enseñanza primaria había sido de $5.11 \%$, para el bienio $1873-1874 .{ }^{8}$

La toma de control sobre recursos antes administrados por gobiernos departamentales y locales por parte del gobierno central se correspondía con las motivaciones políticas de la centralización. De esa manera, la facción gobernante del Partido Civil trataba de consolidar su autoridad sobre la población en general, y los poderes locales en particular. Por una parte, se alentaba a la población a asociar a las autoridades nacionales con el acceso a la instrucción primaria. Al mismo tiempo, los líderes más

${ }^{6}$ Villarán 1914: 223. Para una descripción y explicación detalladas de la organización descentralizada de la educación pública primaria en el Perú del siglo XIX, ver Espinoza 2013: capítulo 3.

7 Ministerio de Justicia, Instrucción y Culto 1907: xxv, 627, 629.

8 Castro 1912: 1029-1032; Dancuart 1907, IX: 192-208. 
jóvenes del civilismo, encabezados por José Pardo, se dotaban de recursos para cooptar a sus opositores y competidores, dentro y fuera del partido, o para imponerse a ellos. Aunque la mayoría de los dirigentes civilistas estaban vinculados a la economía exportadora, el partido en sí mismo no era un bloque monolítico, sino más bien un grupo de facciones de las clases alta y media de diversas regiones del país con intereses económicos diferenciados. Estas facciones frecuentemente se unían bajo líderes específicos, y se dividían siguiendo líneas personales y familiares. ${ }^{9}$ Además de competir con otros partidos políticos, Pardo y sus aliados tenían que lidiar con una generación más antigua de civilistas. Este grupo era encabezado por el abogado Isaac Alzamora, quien fue vicepresidente del Perú durante cuatro años (1899-1903). Tras el repentino deceso del presidente civilista Manuel Candamo (1903-1904), Alzamora esperaba ser el candidato de su partido en la siguiente elección. En lugar de ello, Pardo obtuvo la nominación y, luego de una breve y encarnizada campaña electoral, se convirtió en presidente del Perú en 1904 . $^{10}$

Tras ser elegido, Pardo encargó al ministro Polar Vargas que sustentara la propuesta de ley reformando la instrucción primaria ante el Congreso. En su discurso ante el Senado, el ministro sostuvo que el proyecto estaba fundado en cuatro principios: geográfico, pedagógico, administrativo y económico. De acuerdo con el primero, la escuela debía corresponderse con el desarrollo intelectual de la población a la que servía. Según Polar Vargas, la mayoría de la población estaba muy «retardada intelectualmente» por su analfabetismo e «insuficiente acumulación intelectual». Por ello, debía recibir una "educación elemental», adecuada a su capacidad, que incluyera lectura, escritura, y aritmética, así como también nociones de moral, de historia y geografía patrias, y de higiene. En el caso de la población indígena, a la que asociaba con las «serranías» y «los campos», el ministro sostenía que era «educable» y «asimilable», pero que había que vencer su desconfianza. Por «instinto de conservación», el resto de la sociedad debía despertar, alentar, y dar esperanza

9 Miller 1982.

${ }^{10}$ Para un examen detallado de las facciones al interior del Segundo Civilismo, ver Ccahuana 2014. 
a los indígenas. De otro modo, la energía de estos se «agotaría». ${ }^{11}$ Con respecto al principio pedagógico, era necesario que la escuela elemental fuera absolutamente gratuita, incluyendo útiles y libros, para cumplir auténticamente la obligatoriedad constitucional de la enseñanza. Por principio administrativo, Polar Vargas se refería a que la dirección de la enseñanza debía estar bajo control del gobierno nacional en tanto «órgano central». El ministro sostenía:

La educación no es necesidad local, que varíe de Provincia a Provincia. Todos, todos igualmente necesitan, la enseńanza primaria. No es la educación interés de campanario, sino de alto interés nacional. No es posible, por lo tanto, dejarla a merced de los recursos más o menos grandes, o más o menos pequeños, de cada provincia. Ni a merced, tampoco, de la mayor o menor competencia de los municipios, de su criterio más o menos amplio en materia de enseñanza. ${ }^{12}$

Por principio económico, Polar Vargas se refería a dotar a la instrucción primaria de un fondo suficiente y estable. De esa manera, se podría contar con las escuelas necesarias a nivel nacional y pagar puntualmente a los maestros.

Además de crear el fondo de instrucción primaria, ya detallado, el poder ejecutivo «reasumía» la dirección y administración de dicha enseñanza. En realidad, el gobierno central siempre había compartido esas responsabilidades con las autoridades locales en mayor o menor medida. Con la reforma propuesta, los concejos provinciales y distritales quedaban sin intervención en el manejo de las rentas de instrucción, en la administración de las escuelas, y en la contratación y despido de docentes. Conservaban tan solo las responsabilidades de nombrar a los jurados de examen para postulantes al magisterio, y de expedir los certificados de asistencia a los docentes. Además, municipalidades y juntas departamentales podían fomentar escuelas primarias de segundo grado. La propuesta de ley creaba una Dirección General de Instrucción Primaria al

${ }^{11}$ Ccahuana argumenta persuasivamente que el Segundo Civilismo, influenciado por el positivismo social, tenía una concepción racializada de la educación (2020).

${ }^{12}$ Ministerio de Instrucción Pública 1906: 7. 
interior del Ministerio de Instrucción, la cual quedaría a cargo de la parte técnica y administrativa de las escuelas. A nivel local, la Dirección estaría representada por inspectores escolares departamentales y provinciales. De esa manera, era abolido el Consejo Superior de Instrucción Pública, órgano colegiado dependiente del ministerio que existía desde 1876, y que cumplía funciones curriculares y de inspección más limitadas.

La discusión del proyecto en el Congreso giró en torno a tres puntos: la centralización total de la instrucción primaria que el proyecto implicaba; las rentas que proporcionarían los fondos para instrucción y su manejo; y los nuevos inspectores escolares, dependientes del Ministerio de Instrucción. Algunos parlamentarios proponían que la centralización fuera gradual y que los municipios que tuvieran capacidad para administrar y costear escuelas siguieran haciéndolo. Otros representantes querían que las autoridades municipales compartieran las funciones supervisoras con los inspectores escolares nombrados por el ejecutivo. También consideraban que era riesgoso que los inspectores fueran nombrados por plazos indeterminados. Ciertos parlamentarios se oponían a que el gobierno nacional se llevara todas las rentas producidas por el mojonazgo, argumentando que este cambio afectaría negativamente las finanzas municipales. ${ }^{13}$ Una de las controversias curriculares del debate fue si la instrucción primaria elemental debía incluir la enseñanza de la doctrina católica, como proponía el proyecto. Los congresistas a favor sostenían que dicha doctrina era la base del Estado, la democracia y el control social. Los que se oponían sostenían que los niños tenían dificultades para comprender una materia tan abstracta. Otros parlamentarios sostuvieron que las escuelas no necesitaban enseñar la doctrina, porque los sacerdotes se encargaban ya de hacerlo en los templos. Para estos representantes, la salvación de las almas era la responsabilidad exclusiva de la Iglesia. ${ }^{14}$ Según rememoraba José Pardo, la Cámara de Diputados rechazó la inclusión de las rentas municipales en el fondo de instrucción primaria. A raíz de ello, el ministro Polar Vargas renunció a su cargo,

${ }^{13}$ Congreso de la República, Cámara de Diputados 1904: 117, 221-240, 345-366; Congreso de la República, Cámara de Senadores 1905: 551-572, 574-592, 597-621.

${ }^{14}$ Congreso de la República, Cámara de Diputados 1904: 117, 141-160. 
lo que el presidente no aceptó. Desconocemos las negociaciones que el ejecutivo pudo tener con el legislativo, pero Polar convenció finalmente a la mayoría de ambas cámaras de que aprobara el proyecto en la legislatura siguiente. ${ }^{15}$ El ejecutivo promulgó la ley el 5 de diciembre de 1905, manteniendo por cierto la enseńanza de la doctrina cristiana en el currículum de la primaria elemental.

\section{EFECTOS TEMPRANOS DE LA CENTRALIZACIÓN}

Uno de los factores que permitió que el primer gobierno de Pardo centralizara la instrucción primaria, y llevara a cabo otras reformas educativas, fue la disponibilidad de fondos fiscales. El presupuesto nacional total se incrementó rápidamente entre 1903 y 1908 debido al crecimiento económico, así como a la introducción de nuevos impuestos directos sobre el consumo de bienes específicos. Como ilustra el siguiente cuadro, la inversión pública total en instrucción primaria tendió a incrementarse entre 1906 y 1920. Decayó tan solo entre 1910 y 1911, a raíz de la crisis financiera mundial iniciada a fines de 1907, que afectó la economía exportadora peruana y las rentas fiscales. ${ }^{16}$ A pesar de ello, los aportes del gobierno central siempre representaron un porcentaje mayor del total que los aportes departamentales. Aunque los gobiernos departamentales, provinciales, y distritales debían ceder el manejo de sus propios recursos educativos, la ley también llevó a la creación de una mayor cantidad de escuelas y puestos docentes. Las autoridades locales podrían beneficiarse con la expansión de la burocracia educativa, en caso de establecer alianzas exitosas con el gobierno nacional y sus representantes. Al mismo tiempo, el gobierno nacional podía ganar más lealtades a nivel local. En el siguiente cuadro podemos apreciar la inversión del gobierno central en comparación con la departamental:

${ }^{15}$ Martín 1996: 415.

${ }^{16}$ Basadre 1983, VIII:133, 343-344. 
Cuadro 1. Cantidades destinadas a la instrucción primaria a nivel departamental y nacional (en soles), 1906-1920

\begin{tabular}{cccc}
\hline Ańo & Departamental & $\begin{array}{c}\text { Nacional (incluyendo } \\
\text { las cantidades } \\
\text { departamentales) }\end{array}$ & $\begin{array}{c}\text { Cantidad departamental } \\
\text { como porcentaje de la } \\
\text { nacional }\end{array}$ \\
\hline 1906 & $304,170.00$ & $2,383,981.49$ & 12.75 \\
1907 & 316.618 .15 & $2,383,981.42$ & 13.28 \\
1908 & $371,396.00$ & $2,383,981.42$ & 15.57 \\
1909 & $414,855.82$ & $2,552,733.20$ & 16.25 \\
1910 & $404,602.43$ & $1,741,860.00$ & 23.22 \\
1911 & $404,602.43$ & $1,741,860.00$ & 23.22 \\
1912 & 400.000 .00 & $2,995,868.58$ & 13.35 \\
1913 & $450,740.00$ & $2,995,868.58$ & 15.04 \\
1914 & $354,778.21$ & $2,002,925.53$ & 17.71 \\
1918 & $589,450.00$ & $3,000,000.00$ & 19.64 \\
1920 & $700,000.00$ & $5,250,000.00$ & 13.33 \\
\hline
\end{tabular}

Fuentes: Presupuestos publicados por el Ministerio de Hacienda y Comercio.

La centralización también dio paso a la expansión de la cobertura de instrucción pública. En 1906, luego de que se pusiera en efecto la ley número 162, los totales de escuelas, docentes, y matriculados se incrementaron, como ilustra el siguiente cuadro. Se puede apreciar, asimismo, una tendencia general al aumento de dichas cantidades hasta 1921. Como ya ha sido mencionado, la disminución en la inversión pública en instrucción primaria afectó el número de escuelas y docentes en años específicos. También avivó críticas a la centralización, como veremos más adelante: 
Cuadro 2. Totales de escuelas primarias, docentes, y matriculados a nivel nacional, 1905-1921

\begin{tabular}{lccc}
\hline Año & Escuelas & Docentes & Matriculados \\
\hline 1905 & 1,425 & 1,657 & 85,000 \\
1906 & 2,157 & 3,039 & 153,506 \\
1907 & 2,262 & 3,071 & 161,660 \\
1908 & 2,339 & 3,246 & 168,184 \\
1909 & 2,156 & 3,244 & 153,901 \\
1910 & 2,002 & 2,804 & 146,400 \\
1911 & 2,005 & 2,839 & 148,271 \\
1912 & 2,203 & 3,190 & 167,814 \\
1913 & 2,242 & 3,261 & 177,941 \\
1914 & 2,263 & 3,312 & 170,843 \\
1915 & 2,273 & 3,246 & 165,724 \\
1916 & 2,296 & 3,304 & 166,002 \\
1917 & 2,322 & 3,382 & 169,806 \\
1918 & 2,693 & 3,882 & 176,689 \\
1919 & 2,693 & 4,351 & 181,211 \\
1920 & 3,338 & 5,059 & 194,701 \\
1921 & 3,334 & 5,065 & 202,828 \\
\hline
\end{tabular}

Fuentes: Ministerio de Justicia, Instrucción y Culto 1907: xxv, 627, 629; Ministerio de Justicia, Culto, Instrucción y Beneficencia 1922, II: 738-739, 740a.

Es posible especular que el incremento de recursos para la instrucción primaria y de plazas docentes fue bienvenido por el magisterio. De hecho, los participantes de la Asamblea Pedagógica de 1889, organizada por la Sociedad de Preceptores de Lima, habían recomendado por unanimidad la centralización de la instrucción primaria, poniéndola bajo autoridades especiales en vez de los concejos municipales. ${ }^{17}$ Los docentes, algunos de los cuales continuaban en ejercicio a principios del siglo XX, también

17 «Asamblea Pedagógica 1889 Instrucción», Archivo Histórico Municipal de Lima [en adelante AHML], 1887 - 1889 Instrucción, f. 46. 
habían sugerido aumentar los fondos públicos destinados las escuelas y mejorar las condiciones de trabajo del magisterio. ${ }^{18}$

Si bien la centralización de la educación aumentó los puestos docentes en general, la cantidad de maestras se incrementó mucho más que la de maestros, como se aprecia en el cuadro 3. Por ello, podemos hablar de una verdadera "feminización" del magisterio a nivel nacional. Los factores que favorecieron este fenómeno requieren mayor investigación, pero se puede proponer algunas hipótesis. En términos ideológicos, ya desde el siglo XIX algunos intelectuales y políticos le atribuían a la mujer un rol crucial en la enseñanza, en tanto se asumía que era naturalmente apta para formar la moralidad de la niñez. En 1876, el Ministro de Instrucción sostenía que la mujer estaba «llamada» al magisterio porque tenía «dotes muy superiores» a las del hombre para ello. ${ }^{19}$ En parte motivado por estas cualidades, presuntamente inherentes, en ese mismo año el gobierno de Manuel Pardo ordenó el establecimiento de la Escuela Normal de Mujeres de Lima, que se abrió dos años más tarde bajo la administración de la Congregación francesa de las Hermanas del Sagrado Corazón. Las becarias debían enseñar en escuelas públicas por cuatro años después de su graduación. Durante las primeras décadas de funcionamiento, además de que el gobierno no pagaba las becas puntualmente, solo una minoría de estudiantes obtuvo el diploma docente y cumplió con enseñar en establecimientos públicos. Por ejemplo, entre 1878 y 1890, la escuela tuvo setenta y seis alumnas, de las cuales desertaron veintidós, se diplomaron veinticuatro, y tan solo dieciocho dirigieron escuelas públicas. En 1908, se estimaba que de alrededor de trescientos estudiantes que había tenido la escuela, solo ciento quince habían culminado sus estudios. ${ }^{20}$

Más allá de los limitados resultados de la Escuela Normal de Mujeres de Lima, la legislación de principios del siglo XX también favorecía la «feminización» del magisterio. Tanto la Ley Orgánica de Instrucción de

18 "Borradores de los Debates de la Asamblea Pedagógica», AHML, 1887-1889 Instrucción, f. 18-43.

${ }^{19}$ Ministerio de Instrucción, Justicia, Culto y Beneficencia 1876: 38.

${ }^{20}$ Ministerio de Justicia. Instrucción, Culto y Beneficencia 1890: 14; Ministerio de Justicia, Instrucción y Culto 1908, I: xxxii. 
1901 como el Reglamento de Instrucción Primaria de 1908 disponían que las escuelas de primaria elemental mixtas (para ambos sexos, entre seis y doce años) estuvieran a cargo de maestras. Asimismo, autorizaban que las escuelas de primaria elemental de varones pudieran encargarse a maestras en caso de carencia de maestros idóneos. ${ }^{21}$

Cuadro 3. Composición del magisterio público por sexo en el Perú, 1890-1924

\begin{tabular}{ccccc}
\hline Año & Hombres & Mujeres & Total & Mujeres como \% del total \\
\hline 1890 & 552 & 258 & 810 & $31.8 \%$ \\
1903 & 1299 & 792 & 2091 & $37.9 \%$ \\
1906 & 1210 & 1558 & 2768 & $56.3 \%$ \\
1907 & 1225 & 1719 & 2944 & $58.4 \%$ \\
1908 & 1262 & 1843 & 3105 & $59.4 \%$ \\
1915 & 1199 & 2047 & 3246 & $63.1 \%$ \\
1916 & 1232 & 2072 & 3304 & $62.7 \%$ \\
1917 & 1260 & 2122 & 3382 & $62.7 \%$ \\
1918 & 1366 & 2516 & 3882 & $64.8 \%$ \\
1919 & 1631 & 2720 & 4351 & $62.5 \%$ \\
1920 & 1576 & 2876 & 4452 & $64.6 \%$ \\
\hline
\end{tabular}

Fuentes: Perú. Ministerio de Justicia, Culto, Instrucción y Beneficencia 1890: 7, 196; Ccahuana Córdova 2020: tabla 5; Perú. Ministerio de Justicia, Culto, Instrucción y Beneficencia 1919: xliv; Perú. Ministerio de Fomento. Dirección de Estadística 1919: 70; Perú. Ministerio de Justicia, Culto, Instrucción y Beneficencia 1920: 35.

Dos factores que debieron tener influencia en la "feminización», aunque resultan difíciles de sopesar debido a la falta de estudios al respecto, fueron la necesidad económica y la disposición de las mujeres para dedicarse a la docencia. Ya en 1876, Teresa González de Fanning argumentó en favor de que se ampliaran las oportunidades laborales para las mujeres, especialmente aquellas que no llegaran a casarse, o quedaran viudas. Paradójicamente, la propia escritora perdió a su esposo durante

21 «Ley Orgánica de Instrucción», El Peruano 61: 35 (26 de marzo de 1901), 183-184; Ministerio de Justicia, Instrucción y Culto 1908, I: 358. 
la Guerra del Pacífico, y se dedicó entonces a la docencia. ${ }^{22}$ Entre 1876 y 1908, según el censo provincial de Lima de este último año, el total de mujeres que se dedicaban a un oficio distinto al de las «labores de su casa» se había incrementado en $24.5 \%$. Un informe adjunto a dicho censo sostenía que ello se había producido:

a causa no solo de las mayores necesidades que les impone nuestro estado económico sino también de una disposición de ellas a independizarse del hombre aprovechando de las nuevas ocupaciones que les proporciona la civilización moderna. ${ }^{23}$

Como se puede apreciar en el cuadro 3, la contraparte de la «feminización» del magisterio público era la disminución en la proporción de maestros. Además, no existía un centro de formación pedagógica para varones. Por ello, durante la Asamblea Pedagógica de 1889, el entonces presidente de la Sociedad de Preceptores de Lima mencionó la necesidad de crear escuelas normales para hombres, para contar con educadores mejor preparados. ${ }^{24} \mathrm{La}$ recomendación fue recogida por el primer gobierno de José Pardo, que decretó el establecimiento de la Escuela Normal de Varones de Lima el 28 de enero de 1905. La escuela se abrió en mayo de ese mismo ańo con los objetivos de formar una mayor cantidad de nuevos maestros, dotados de los conocimientos más modernos, y de capacitar mejor a los docentes ya existentes. ${ }^{25}$ Para evitar las dificultades experimentadas con la escuela normal de varones que había funcionado en Lima entre 1859 y 1869, el gobierno se esforzó por asegurarle una organización apropiada y suficientes recursos a la nueva institución. ${ }^{26}$ Por consejo del primer director, el educador belga Isidoro Poiry, la escuela fue estrictamente una institución de educación profesional, que solamente aceptaba alumnos que se hubiesen graduado de secundaria. Poiry quería formar a los normalistas en la "pedagogía científica», con

22 González de Fanning 1892: 286-293.

${ }^{23}$ Dirección de Salubridad Pública 1915, I: 109.

24 "Asamblea Pedagógica 1889 Instrucción», AHML, 1887 - 1889 Instrucción, f. 15v.

25 Poiry 1905: 2-5.

${ }^{26}$ Acerca de aquellas dificultades, ver Espinoza 2016: 63-64. 
buen conocimiento de la naturaleza física, moral e intelectual del niño. Consideraba importante que los preceptores tuvieran saberes extensos y diversos, dada la importancia de su responsabilidad. Entre dichos conocimientos incluía la pedagogía y los ramos de enseñanza primaria, así como también nociones de filosofía, historia, literatura, antropología, sociología y ciencias naturales. ${ }^{27}$

La Escuela Normal reclutó a sus primeros alumnos entre sectores medios y altos de Lima y del interior del país. Los requisitos de admisión no estaban al alcance de los sectores menos favorecidos. Cada postulante debía presentar un diploma de secundaria completa y, en caso de ingresar, debía depositar una garantía de trescientos soles. El gobierno solamente devolvía este depósito una vez que el estudiante había obtenido su título y trabajado para el Estado durante al menos tres años. Para ser becario del gobierno, se necesitaba haber obtenido notas sobresalientes en dos tercios de los cursos de media. Los alumnos de paga abonaban veinticinco soles mensuales para ser internos, diez soles para ser cuarto internos, cinco soles para ser externos. ${ }^{28} \mathrm{~A}$ pesar de su costo, los estudios en la Normal solo duraban dos años (que incluían también prácticas en la escuela anexa), mientras que conseguir un título universitario tomaba entre tres y siete años. ${ }^{29}$ Estudiar en la Normal resultaba atractivo para aquellos jóvenes varones que no podían posponer un empleo a tiempo completo por un lapso más prolongado. En el caso de los graduados de provincias, quienes debían alojarse en la Normal, viajar a la capital les daba la oportunidad de escapar a las limitaciones políticas y sociales que enfrentarían en sus lugares de origen. Una vez en Lima, tenían la oportunidad de crear nuevas conexiones personales y profesionales, que podían resultar útiles al regresar a su lugar de origen.

Las reformas educativas llevadas a cabo por el gobierno de José Pardo representaban oportunidades laborales positivas y mejor reconocimiento social para el magisterio. En 1911, algunos graduados de la Normal afirmaban que su alma mater atrajo inicialmente varios «jóvenes idealistas»,

\footnotetext{
27 Poiry 1905: 7.

${ }^{28}$ Ministerio de Instrucción Pública 1907: 8-9.

29 «Ley Orgánica de Instrucción», 199-200.
} 
interesados no solo en "contribuir al progreso del país», sino también en «promesas de remuneración y consideraciones». El gobierno originalmente ofreció a los normalistas un salario mensual de ciento veinte soles, más el alquiler de su vivienda, y cuarenta soles por cada conferencia pedagógica que dieran. ${ }^{30}$ Atraídos por las oportunidades, trescientos treinta y cuatro jóvenes se graduaron de la Escuela Normal entre 1906 y $1921 .{ }^{31}$ Con respecto a los docentes comunes, no graduados de la Normal, no se ha encontrado evidencia de que el gobierno de Pardo hiciera mal uso de la prerrogativa de despedir maestros. Una notificación oficial que el ministro envió al prefecto de Huánuco en enero de 1906 decía que el gobierno deseaba conservar a todos los maestros de escuela pública que estuviesen cumpliendo sus responsabilidades adecuadamente. ${ }^{32}$

\section{DIFICULTADES CONSIGUIENTES A LA CENTRALIZACIÓN Y ESTRATEGIAS} MAGISTERIALES

La relativa estabilidad política y económica que permitió a José Pardo iniciar la centralización de la instrucción primaria se deterioró rápidamente después de su primer mandato presidencial. La generación más antigua de civilistas no aprobaba a Augusto B. Leguía (1908-1912), el sucesor que Pardo eligiera, porque lo consideraban excesivamente ambicioso, oportunista, y no confiable para el partido. Como ministro de Economía durante el gobierno de Pardo, Leguía implementó medidas fiscales que lo malquistaron con algunos líderes del interior. Algunos miembros de los partidos Demócrata y Liberal intentaron iniciar una rebelión contra el gobierno inmediatamente antes de las elecciones de 1908, tentativa que fue rápidamente reprimida por las autoridades nacionales. Un grupo de demócratas secuestró a Leguía un año más tarde, tratando de forzarlo a renunciar. Militares leales rescataron al presidente, a lo que siguió una violenta represión de los rebeldes.

${ }^{30}$ Congreso Regional de Normalistas 1911: 119-123.

${ }^{31}$ Ministerio de Instrucción. Dirección General de Enseñanza 1928: 32

32 "Oficio no. 186 dirigido al prefecto de Huánuco», 14 de febrero de 1906, Archivo Central del Ministerio de Educación [en adelante ACME], Dirección General de Instrucción. Resoluciones Ministeriales. De julio a marzo 1905-06. 
En 1911, los civilistas disidentes formaron una minoría parlamentaria hostil a Leguía denominada El Bloque, que obstaculizó varias de las iniciativas presidenciales. El arresto del joven catedrático civilista José de la Riva-Agüero en septiembre de 1911, por haber criticado al gobierno y alabado a los rebeldes de 1909, provocó choques entre la policía y los estudiantes universitarios. El gobierno liberó a Riva-Agüero tras la muerte de un estudiante durante los disturbios. ${ }^{33} \mathrm{El}$ primer gobierno de Leguía quedó empantanado en los conflictos con sus opositores, dentro y fuera de su partido.

Además de las dificultades políticas que Leguía tuvo que enfrentar, entre 1909 y 1910 se redujo el gasto fiscal en instrucción primaria, lo que perjudicó al magisterio. Primero, el gobierno dejó de pagar las conferencias pedagógicas dadas por los graduados de la Escuela Normal; luego, redujo su salario a cien soles mensuales; finalmente, dejó de pagar por el alquiler de sus viviendas. ${ }^{34}$ En septiembre de 1914, el diputado Gerardo Balbuena se quejó en su cámara de que no se había pagado a los maestros por un lapso no precisado. Un mes más tarde, el congresista Arturo F. Alva, quien fuera inspector escolar durante el primer gobierno de Pardo, se quejó de que el ejecutivo había cesado a más de cien maestros, incluyendo graduados de la Escuela Normal. Aparentemente, fue una medida dirigida a reducir el gasto fiscal. Alva pidió al gobierno que reconsiderara la decisión y volviera a contratar a los perjudicados. ${ }^{35}$

Las dificultades materiales en la instrucción primaria atizaron las críticas a la centralización y a los inspectores escolares en particular. Ya en octubre de 1909, los senadores Arturo E. Vidal (Ancash) y Luis Sánchez Ferrer (La Libertad) propusieron que se restituyeran las responsabilidades escolares a las autoridades municipales, aboliendo los inspectores escolares. ${ }^{36}$ En enero de 1912, durante el último año de Leguía en la

\footnotetext{
33 Basadre 1983, VIII: 218, 275-279, 332-333.

${ }^{34}$ Congreso Regional de Normalistas 1911: 119-123.

35 Congreso de la República, Cámara de Diputados 1914: 353-359, 392-393.

${ }^{36}$ Congreso de la República, Cámara de Senadores 1909: 563. El debate en torno al presupuesto nacional de 1910 aparece en Congreso de la República, Cámara de Diputados 1910: 458-472.
} 
presidencia, algunos senadores se quejaron de que el gobierno había engañado a los concejos municipales. Según estos congresistas, las autoridades nacionales habían obligado a las municipalidades a entregar parte de sus recursos bajo la premisa de que el Estado se ocuparía de la instrucción primaria. Sin embargo, el gobierno central había reducido su inversión en las escuelas en tal medida que, según ellos, estas eran pagadas casi exclusivamente con los antiguos fondos ediles. ${ }^{37}$

Quizá el aspecto más contencioso de la centralización fue la introducción de inspectores escolares nombrados y supervisados por el gobierno central. Dichos funcionarios eran seleccionados por el Ministerio de Instrucción, controlado primero por la facción civilista de José Pardo, y luego por el gobierno de Leguía. Sus responsabilidades incluían la distribución de los fondos escolares y la contratación y el despido de maestros. Los inspectores escolares tenían poder político porque eran agentes del Estado a nivel local. Además de llevar a cabo su función pública, también podían representar los intereses partidarios de las autoridades nacionales y proporcionar información sobre las condiciones locales. El Ministerio de Instrucción nombró los primeros inspectores escolares de provincias, cerca de cien, en $1906 .{ }^{38}$ Eran un grupo profesional heterogéneo que incluía abogados, escritores, educadores, y burócratas. El primer inspector regional de Lima fue Juan E. Díaz, un educador que anteriormente había trabajado para el concejo municipal de la capital. En el Callao, el primer inspector escolar provincial fue el periodista y escritor Aurelio Arnao, posteriormente senador por Ancash (1911-1918). José Francisco Iberico, otro escritor, fue nombrado inspector escolar de Andahuaylas. Iberico obtuvo su doctorado en derecho en la Universidad de Arequipa a poco de ser nombrado; posteriormente, fue inspector escolar departamental de Cuzco y Apurímac. Pascual Segundo Macedo, inspector escolar de la provincia de Ayaviri (Puno), era también un abogado especializado en derecho minero en la Universidad de San Marcos. El Ministerio de

37 Congreso de la República 1912: 206-212.

38 "Inspectores provinciales de instrucción primaria», 12 de marzo de 1906. ACME, Dirección General de Instrucción Pública. Oficios y Resoluciones. 23 de noviembre al 17 de marzo, 1905-1906. 
Instrucción confió a estos inspectores que representaran los intereses públicos en general, pero también los de la facción a cargo del gobierno central.

Consecuentemente, no es de extrañar que las críticas a los inspectores escolares se centraran en su influencia sobre la política local. En octubre de 1911, el senador Joaquín Capelo, miembro del Partido Demócrata, opuesto al Partido Civil del presidente Leguía, sostuvo que los inspectores escolares eran agentes electorales antes que funcionarios educativos. Según Capelo, los inspectores obtenían su nombramiento a través de sus patrones políticos, y a cambio se esperaba que consiguieran votos para sus patrocinadores. Agregó que los inspectores escolares también abusaban de los maestros, obligándoles a que votaran por sus candidatos favoritos, a riesgo de multarlos o chantajearlos. Otros senadores sostenían que los inspectores intentaban nombrar a sus paniaguados como directores de las escuelas públicas. ${ }^{39}$ En noviembre de 1912, Capelo reiteró su crítica a los inspectores escolares, afirmando que solo se debía nombrar como tales a maestros experimentados o graduados de la Escuela Normal. ${ }^{40}$ En respuesta a las quejas, así como también debido a las dificultades financieras, el gobierno nacional redujo gradualmente el número de inspectores escolares de unos cien a ochenta, y posteriormente a alrededor de sesenta. En 1910, el Ministerio de Instrucción impuso requisitos más exigentes para ser inspector: tener título de bachiller o ser graduado de la Escuela Normal o maestro de segundo grado, y tener al menos cuatro años de experiencia docente. ${ }^{41}$ El gobierno de Leguía intentó así llegar a un compromiso en torno a los inspectores sin llegar a abolirlos, que era en parte lo que la oposición perseguía.

A pesar de las medidas tomadas por el ejecutivo, la oposición insistió en sus críticas a los inspectores escolares. Sin embargo, no tuvieron oportunidad de forzar más cambios durante la presidencia de Guillermo Billinghurst (1912-1914). En agosto de 1913, el diputado Carlos E. Uceda propuso que se aboliera a los inspectores escolares provinciales

${ }^{39}$ Congreso de la República, Cámara de Senadores 1911: 829-833, 864-868.

${ }^{40}$ Congreso de la República, Cámara de Diputados 1912: 284.

${ }^{41}$ Ministerio de Justicia, Culto, Instrucción y Beneficencia 1910, I: xxxv. 
y que se transfirieran sus responsabilidades a los inspectores distritales. Estos funcionarios reportarían directamente a un supervisor departamental. ${ }^{42}$ Durante el gobierno de Billinghurst, se produjo una profunda división entre el presidente y el Congreso. Billinghurst llegó al poder con el apoyo de los trabajadores y tomó una serie de medidas para beneficiarlos. Entre ellas, estaba la concesión de la jornada de ocho horas para los trabajadores portuarios del Callao, así como el reconocimiento y regulación del derecho a huelga. Los congresistas se opusieron a estas medidas, luego de lo cual temían que Billinghurst disolviera el Congreso, lo que llevó a algunos de ellos a conspirar contra el presidente. Cuando Billinghurst intentó implementar un nuevo presupuesto sin aprobación congresal, los conspiradores pidieron a los militares que intervinieran. ${ }^{43}$ El 4 de febrero de 1914, el general Óscar Benavides depuso a Billinghurst, dando así la oportunidad al Congreso para que tomara medidas con respecto a los inspectores escolares.

Una vez en el poder, Benavides transfirió las responsabilidades de los inspectores escolares departamentales a los prefectos, quienes reportaban directamente al presidente. Luego, en diciembre de 1914, el legislativo discutió un proyecto para abolir los inspectores provinciales y distritales, y transferir sus responsabilidades a los concejos municipales. Solo quedarían los inspectores de departamento en sus capitales respectivas. Un grupo de diputados propuso abolir a todos los inspectores escolares, argumentando que eran un fracaso total. Según ellos, muchos inspectores eran ignorantes e inmorales, y se dedicaban exclusivamente a la política local y a su beneficio personal. Estos parlamentarios sostenían que los gobiernos municipales tenían un mayor conocimiento de las condiciones locales y que podrían manejar las escuelas mucho mejor. ${ }^{44}$ Una de las voces solitarias que defendió a los inspectores escolares fue la del parlamentario Gustavo Manrique Salazar, quien sugirió que se debía crear inspectores regionales con sede en Lima, Trujillo, y Arequipa. Manrique consideraba que había razones legales y administrativas para

\footnotetext{
42 Congreso de la República, Cámara de Diputados 1913: 201.

43 Blanchard 1997: 251-273.

${ }^{44}$ Congreso de la República, Cámara de Diputados 1914: 549-556, 562-570.
} 
transferir la supervisión de las escuelas a los gobiernos municipales, pero que también era necesario crear un cuerpo especializado que tuviera voz sobre ellas. La cámara rechazó la propuesta de Manrique. ${ }^{45}$ En enero de 1915, Benavides aprobó una ley preparada por el Congreso que abolía a todos los inspectores escolares. El parlamento sostuvo que la causa era la crisis fiscal del país. Los gobiernos municipales asumirían las responsabilidades de los inspectores hasta que la situación fiscal mejorara y una vez que el ejecutivo presentara un proyecto para restablecer a dichos funcionarios. ${ }^{46}$ La posibilidad quedó abierta, pero Pardo, el sucesor de Benavides, no logró restablecerlos durante su segunda presidencia.

La abolición de los inspectores escolares en 1915 fue un revés temporal para la centralización administrativa y pedagógica de la instrucción primaria. Resulta revelador que el general Benavides, que ascendiera al poder con el apoyo de políticos que resentían tener un poder ejecutivo fortalecido, y que además se oponían a las reformas sociales, haya abolido a los inspectores escolares después de asumir el mando. Es bastante probable que algunos inspectores se hubieran involucrado en la política electoral. Sin embargo, los congresistas que cuestionaban a la institución del inspector no querían que se reformara o mejorara, sino que se la aboliera. La creación de los inspectores había alterado el equilibrio del poder a nivel local. Los inspectores asumían las prerrogativas administrativas y financieras que los concejos municipales habían ejercido previamente en la esfera educativa. Además, su dependencia del gobierno central hacía que fueran rivales potenciales en la política local. La abolición de los inspectores, y el retorno de sus funciones a los gobiernos municipales, era un intento de restablecer el equilibrio del poder. El Congreso, claro está, no revirtió el compromiso que el gobierno nacional había hecho de invertir una mayor cantidad de dinero, de manera regular, en la instrucción primaria. Quienes tenían el poder a nivel local deseaban tener acceso a una cantidad mayor de fondos públicos y, al mismo tiempo, mantener el control sobre su uso político.

${ }^{45}$ Congreso de la República, Cámara de Diputados 1914: 573-587.

46 "Ley 2094. Supresión de las inspecciones de instrucción primaria», 2 de enero de 1915, Archivo Digital de la Legislación del Perú [en adelante ADLP]. 
La Primera Guerra Mundial (1914-1918) tuvo inicialmente un impacto negativo sobre la economía peruana. Hizo más difícil que las exportaciones peruanas alcanzaran los mercados europeos, encareciendo el precio del transporte y de las importaciones, y entorpeciendo el acceso a crédito. El desempleo fue creciendo a medida que las actividades exportadoras caían, mientras el costo de vida se incrementaba y las condiciones de la clase obrera empeoraban. ${ }^{47}$ Benavides se esforzó por dejar el gobierno lo antes posible para dejar que los políticos lidiaran con estas dificultades. En agosto de 1915, una convención en la que participaron los partidos Civil, Liberal, y Constitucional eligió presidente a José Pardo. El segundo mandato de Pardo (1915-1919) se caracterizó por un mayor autoritarismo que el primero. A pesar de ello, el presidente no logró que el Parlamento aprobara el restablecimiento de los inspectores escolares. Pardo pidió al Congreso que aboliera la ley 2094 en 1915 y 1917 con el argumento de que los concejos municipales habían sido incapaces de manejar la educación primaria eficientemente y de hacer buen uso de los fondos escolares. ${ }^{48}$

El Congreso discutió los pedidos del presidente, pero dilató tomar medidas concretas. Durante el debate en la Cámara de Diputados en 1917, un grupo de congresistas se opuso al proyecto sosteniendo que los inspectores escolares debían nombrarse por sus conocimientos pedagógicos y no solo por intereses políticos. Otros apoyaron el inmediato restablecimiento de los inspectores, afirmando que los concejos municipales habían demostrado su incapacidad para supervisar las escuelas. Un tercer grupo quería posponer una decisión en torno a los inspectores hasta que toda la ley de educación fuera reformada. ${ }^{49} \mathrm{El}$ Congreso eligió la tercera opción, lo que llevó a Pardo a establecer una comisión para que revisara el nuevo proyecto de ley de educación, el cual había sido preparado por un grupo anterior en 1910, durante el primer gobierno

\footnotetext{
${ }^{47}$ Blanchard 1982: 100-105.

${ }^{48}$ Congreso de la República 1915: 8-10; Perú. Congreso 1919 (1917): 11-14; Ministerio de Justicia, Instrucción, Culto y Beneficencia 1917: xxxvii-xxxviii.

${ }^{49}$ Congreso de la República, Cámara de Diputados 1917: 144-162.
} 
de Leguía. ${ }^{50}$ Fue recién en 1921, luego de que Leguía asumiera nuevamente la presidencia, que el gobierno logró restablecer a los inspectores escolares dependientes del poder ejecutivo. ${ }^{51}$

Los conflictos políticos partidarios afectaron la vida profesional y personal del magisterio público. No podía ser de otro modo, puesto que los docentes de escuelas públicas eran nombrados por el gobierno central, por lo que habían pasado a ser no solo actores educativos sino también representantes del Estado. Dada la incapacidad o falta de voluntad del gobierno central para protegerlos, el magisterio recurrió a varias estrategias colectivas para defender sus intereses. Dichas estrategias incluyeron la creación de asociaciones de enseñantes, la publicación de revistas especializadas y la realización de encuentros magisteriales. Los graduados de la Escuela Normal de Varones de Lima asumieron un rol de liderazgo en dichas estrategias.

Ya desde la década de 1870, los docentes capitalinos habían estado desarrollando una identidad colectiva, a pesar de la falta de una formación pedagógica común, a través de charlas, publicaciones especializadas, y la Sociedad de Preceptores de Lima. ${ }^{52}$ La creación de la Escuela Normal de Varones contribuyó a renovar las ideas pedagógicas del magisterio y a consolidar gradualmente lo que el investigador Javier García Liendo ha llamado una "cultura magisterial normalista", de la que creemos participaron también docentes no vinculados a dicha escuela. Esta cultura estuvo influenciada por la llamada Escuela Nueva o Activa, y se caracterizó por tratar de adecuar la enseńanza a la realidad local de los estudiantes, integrando a todos los miembros de su comunidad en el proceso educativo. También planteó una concepción de las escuelas como factores del progreso local, no limitadas a comunicar conocimientos tradicionales, y promovió una noción de los docentes como agentes de cambio social y cultural. ${ }^{53}$ Entre quienes introdujeron los planteamientos

${ }^{50}$ Congreso de la República 1919: 10-12.

${ }^{51}$ Ministerio de Justicia, Instrucción, Culto y Beneficencia 1920: 10-13, 21-26; Ministerio de Justicia, Instrucción, Culto y Beneficencia 1922: 19-20.

52 Espinoza 2016: 66-68.

53 García Liendo 2017: 381. 
de la Escuela Nueva en la Normal, estuvo Joseph MacKnight, su segundo director (1911-1915).

MacKnight, miembro de una misión pedagógica estadounidense contratada por el primer gobierno de Leguía, fue quien divulgó las ideas de los filósofos pragmáticos norteamericanos William James y John Dewey en la Escuela Normal. ${ }^{54}$ James (1842-1910) fue autor de Talks to Teachers on Psychology. And to Students on Some of Life's Ideals, cuya traducción al castellano se convirtió en uno de los libros de texto básicos de la Normal. A partir de sus investigaciones psicológicas, James formuló la idea de la mente como una guía que podía adaptarse de manera flexible a las diversas experiencias y desafíos vitales. En su obra, James explicaba conceptos psicológicos como la asociación de ideas, el interés y la atención, la apercepción —o la asociación de ideas viejas y nuevas- $-\mathrm{y}$ la voluntad. ${ }^{55}$ Para James, las responsabilidades principales del docente eran familiarizarse con los instintos naturales del niño e inculcar a sus alumnos hábitos útiles para su vida. La originalidad de James radicaba en enfatizar los procesos mentales del niño, sus experiencias, y sus necesidades prácticas como ejes de la educación.

En cuanto a Dewey (1859-1910), La Escuela Moderna, la revista mensual de la Normal que apareció entre 1911 y 1915, publicó traducciones de sus obras Mi credo pedagógico y del capítulo segundo de La escuela y la sociedad. Dewey consideraba que los factores psicológicos y sociales eran importantes en el proceso educativo. Para él, una educación efectiva preparaba al niño para compartir el legado humano, asumir el control de sus propias capacidades y contribuir al bienestar de la sociedad. Dewey sostenía que la educación debía ser una reconstrucción continua de la experiencia social cambiante del niño. La escuela misma era una forma de vida comunal, por lo que debía incorporar y expandir las experiencias que el niño tenía en su hogar y en su comunidad más amplia. Dewey criticaba a las escuelas tradicionales por tratar

${ }^{54}$ Encinas 1932: 153.

55 James 1914. Joseph A. MacKnight, el director de la Escuela Normal, recomendó repetidas veces la lectura del libro de James a todos los profesores. Véase MacKnight 1911b: 35-36; 1913: 43-44; 1914: 201-202. 
a los niños como oyentes pasivos, enfatizando el recitado como método de enseñanza. El sistema más eficaz era estudiar y seguir los instintos, capacidades, e intereses naturales del niño. Para Dewey, el medio más efectivo para la reforma y progreso sociales era una educación organizada tal como lo proponía. ${ }^{56}$

Además de adoptar y aplicar las ideas de James y Dewey, los normalistas también acogieron el concepto de psicología infantil y el estudio experimental del desarrollo del niño. La psicología infantil se refería no solo al desarrollo normal de las funciones mentales del niño, ya examinadas por James y Dewey, sino también a posibles patologías. ${ }^{57}$ Los normalistas estaban particularmente interesados en establecer el grado de inteligencia, o capacidad para aprender, que el niño tenía. Esta capacidad, pensaban, se veía afectada no solo por las características psicológicas del niño, sino también por otros factores tales como su medio ambiente geográfico, los rasgos físicos heredados y adquiridos, y el entorno social. La Normal introdujo clases sobre paidología, entonces una disciplina novedosa, en la cual los estudiantes de dicha escuela evaluaban experimentalmente todos los factores que afectaban la capacidad del niño para aprender. En el caso específico de la psicología infantil, la paidología evaluaba variables tales como percepción, atención, memoria y asociación de ideas, así como imaginación, conciencia, volición y capacidades lingüísticas. Además, la Normal fue una pionera en el uso de la escala de inteligencia y las pruebas relativas a la misma, formuladas por los psicólogos franceses Alfred Binnet y Theodore Simon, así como también de la escala alternativa creada por los científicos norteamericanos Robert Yerkes y James Bridges. Profesores, estudiantes, y graduados de la Normal publicaron estudios relacionados con estas innovaciones pedagógicas. ${ }^{58}$

Como ha sido mencionado, una de las contribuciones de la Escuela Normal de Varones a la nueva cultura magisterial fue la premisa de que los docentes debían ser agentes de cambio. El maestro ideal era

\footnotetext{
${ }^{56}$ Dewey 1913a, 1913b, 1913c, 1913d, 1914a, $1914 b$.

${ }^{57}$ Encinas 1912b: 1-9; 1912a: 119-121.

${ }^{58}$ Infante 1914b: 137-142; Garmendia 1914: 223-227; MacKnight y Chávez Ratto 1915: 34-38; Luna 1913; MacKnight 1916.
} 
un promotor de virtudes, nacionalismo, y progreso. Pedro L. Aponte, director de escuela estatal que publicó varios artículos en La Escuela Moderna, llamó a la enseñanza un «sagrado ministerio». Al igual que Jesucristo, los maestros revelaban la verdad a sus pupilos y los guiaban hacia el bien. Como el Mesías, los educadores debían estar listos para enfrentar la indiferencia, la ingratitud, y la traición. ${ }^{59}$ En otros artículos publicados en la misma revista, se planteó que los maestros no debían limitar su influencia a la escuela, sino también ser líderes locales, proporcionando conocimientos y ejemplos de moralidad a los alumnos, las familias, y la comunidad. La contribución de los docentes a forjar la lealtad hacia la nación era crucial. Aponte llegó incluso a afirmar que el docente era el «creador» de la patria a través de su influencia temprana y amplia en la sociedad. Dos de las principales responsabilidades de los educadores eran fomentar el nacionalismo y preparar a los niños para que fueran futuros ciudadanos. Los maestros debían presentar a los alumnos ejemplos de personalidades históricas que habían hecho contribuciones al bienestar del país. El estudio de la historia nacional daría forma a la volición del niño, llevándolo a ser patriota, obediente, y eventualmente un ciudadano reflexivo que contribuiría a la prosperidad de la patria. ${ }^{60}$ Las escuelas efectivas eran más importantes para el progreso del país que los recursos materiales. Una educación útil regeneraba a las personas y mejoraba las condiciones sociales. ${ }^{61}$

A medida que surgían dificultades en su vida laboral, los normalistas crearon asociaciones magisteriales, organizaron conferencias profesionales, y publicaron sus propias revistas. Usaron estos espacios para discutir cuestiones pedagógicas y condiciones laborales, presentar su agenda a las autoridades, afirmarse como especialistas educativos, y crear relaciones de solidaridad con los maestros no graduados de la Normal. A comienzos de 1911, se llevó a cabo el Primer Congreso Regional de Normalistas en Arequipa. Estuvo motivado, en parte, por influir en la

${ }^{59}$ Aponte 1911: 100-102.

${ }^{60}$ Infante 1914a: 11-14; Aponte 1911: 37-40 y 1912: 9-14; Bouroncle 1911: 104-105; Ugarte 1911: 245-247.

${ }^{61}$ MacKnight 1911a: 1. 
comisión oficial creada un año antes por Leguía para proponer modificaciones a la ley número 162. Las discusiones del evento se centraron en las condiciones de vida y de trabajo de los maestros primarios. Los participantes sostuvieron que ellos no podían desempeñar sus labores correctamente mientras se les pagaran bajos salarios y tuvieran un reconocimiento social reducido. Los maestros necesitaban tener un ingreso que cubriera sus gastos de vida y les permitiera mantenerse independientes del clientelismo político. Los normalistas también deseaban contar con aprobación oficial para tener nombramientos paralelos que fueran compatibles con sus labores docentes, presumiblemente para ser aceptados por las comunidades donde trabajaban e integrarse mejor a ellas. El congreso alentó al gobierno a mejorar el ingreso y los beneficios de jubilación de los maestros, incrementando gradualmente su salario según su antigüedad y liberando los nombramientos docentes de las influencias políticas. ${ }^{62}$

Un año después del congreso de Arequipa, la Sociedad de Preceptores de Trujillo auspició el Primero Congreso Pedagógico Regional del Norte. Los participantes fueron no solo graduados de la Normal, sino también otros maestros de escuelas públicas y privadas. Los asistentes aprobaron las recomendaciones hechas por sus pares del sur en lo que respecta a los medios con que mejorar las condiciones de los docentes. Subrayaron la necesidad de compensar a los maestros según sus logros, experiencia y el costo de vida del lugar en donde trabajaban. También se refirieron a la necesidad de liberar los nombramientos de toda influencia política. ${ }^{63}$ Asimismo, el congreso discutió posibles medios para incrementar la estimación social hacia los maestros. El normalista Luis Enrique Galván sostuvo que los maestros carentes de una sólida vocación profesional se veían fácilmente influidos por los padres que descuidaban la educación de sus hijos. Para lograr la colaboración entre la escuela y las familias, el congreso aconsejó a los maestros que se asociaran con otros educadores a nivel local, popularizaran nuevas ideas pedagógicas y organizaran

${ }^{62}$ Congreso Regional de Normalistas 1911: 51-70, 124-137.

${ }^{63}$ Congreso Pedagógico Regional del Norte 1912: 173-175. 
ceremonias escolares abiertas a la población para conmemorar las fiestas patrióticas. También se alentó a los maestros a que entablaran amistad con los padres y los animaran a que crearan sus propias asociaciones de apoyo a la educación. ${ }^{64}$ El congreso de Trujillo enfatizó no solo las condiciones materiales de los docentes, sino también en su relación con las comunidades locales.

Los graduados de la Normal también deseaban ser reconocidos como especialistas educativos, para así ganar mayor apoyo oficial y estatus social. Para alcanzar esta meta, crearon asociaciones profesionales en todo el país y promovieron la publicación de revistas pedagógicas. Los normalistas intentaron incorporar a los maestros comunes a sus iniciativas, al mismo tiempo que mantenían un papel dirigente. Para 1913, dirigían diecinueve de las treinta y tres asociaciones de maestros del país; además, los graduados de la Normal también publicaban nueve revistas de educación distintas. ${ }^{65}$ La Asociación Nacional de Normalistas auspiciaba La Educación Nacional, revista fundada por José Antonio Encinas, Amador Merino y Luis C. Infante, que apareció entre 1913 y 1921. Dicha publicación incluía artículos de graduados de la Normal y otros educadores. Fue una revista abiertamente crítica de la falta de apoyo oficial para los educadores, así como de la influencia negativa que los conflictos partidarios tenían sobre la instrucción pública. En agosto de 1913, acusó al Congreso de no haber realizado nada positivo por la educación pública desde 1909. Según la publicación, el Congreso carecía de un proyecto educativo sólido, no había proporcionado fondos adecuados a las escuelas, descuidaba las condiciones de vida de los maestros y posponía reformas necesarias en la legislación educativa. ${ }^{66}$

Una de las principales causas abrazadas por «La Educación Nacional» fue la del incremento salarial del magisterio público. En 1913, la comisión nombrada por el expresidente Leguía para reformar la ley de educación de 1905 presentó finalmente sus conclusiones, luego de tres años de trabajo. La comisión sugirió que cada graduado de la Escuela Normal

\footnotetext{
${ }^{64}$ Congreso Pedagógico Regional del Norte 1912: 24-30.

${ }^{65}$ Prialé 1913a y 1913 b.

66 «El parlamento y la instrucción pública» 1913: 1-10.
} 
recibiera un aumento salarial por cada cinco años que hubiese trabajado para el Estado. Amador Merino, un graduado de la Normal, coincidió con esta propuesta, argumentando que mejoraría la estimación social hacia los educadores. ${ }^{67}$ Poco después, un grupo de educadores públicos insistió en solicitar a la Cámara de Diputados que les diera aumentos graduales en su salario. Los solicitantes eran tanto graduados de la Normal como otros docentes, quienes argumentaban que su baja compensación impedía que ocuparan el lugar que merecían dentro del «cuadro de la organización social». ${ }^{6}$

Las relaciones entre los docentes graduados de la Escuela Normal de Varones y aquellos que no lo eran no fueron siempre cordiales. Ello se hizo evidente cuando el gobierno nacional fijó una nueva escala salarial para el magisterio de Lima y Callao en julio de 1918, dando preferencia a los normalistas. En un extremo, un director de un centro escolar de primaria completa, graduado de la Normal, recibiría ciento treinta y cinco soles mensuales, mientras en el otro, un maestro auxiliar no normalista ganaría ochenta soles. ${ }^{69}$ En reacción a esta medida, un grupo de preceptores que no eran graduados de la Normal pidió al legislativo que incrementara su salario mensual a cien soles. Para costear este incremento, los solicitantes sugirieron al Congreso que redujera el sueldo mensual de los normalistas a noventa soles. Ángel Alfredo Prialé, un normalista, se opuso a esta sugerencia argumentando que los requisitos de ingreso a las escuelas normales, así como las condiciones para graduarse, eran mucho más exigentes que aquellos requeridos para conseguir un diploma de enseñanza común. Prialé mencionó que los graduados de la Normal invertían más tiempo y dinero en la obtención de su título, y que tenían mejor formación pedagógica que los maestros comunes. ${ }^{70} \mathrm{El}$ Congreso discutió el pedido, pero no tomó ninguna decisión.

\footnotetext{
${ }^{67}$ Merino Reyna 1913: 6-8.

68 «Memorial» 1913: 17-20.

69 «Ley No. 2766. Sueldos de los Preceptores de las Escuelas Fiscales», 6 de julio de 1918, ADLP.

${ }^{70}$ Prialé 1918: 6-13.
} 
La Educación Nacional, publicación de la Asociación de Normalistas, también dedicó varios artículos a la cuestión de los inspectores escolares. Los normalistas esperaban tener mayor acceso a las inspectorías escolares, cargos que conllevaban mayor autoridad. En 1911, Humberto Luna, un normalista, se ocupó de la influencia que el clientelismo tenía sobre el nombramiento de los maestros de escuela y de los inspectores. Luna sostenía que las inspectorías se habían convertido en cargos políticos antes que puestos pedagógicos, y que los partidos políticos y los congresistas buscaban repartirlas entre quienes los apoyaban. ${ }^{71}$ En agosto de 1913, el autor de un artículo publicado en la misma revista se quejó de que los graduados de la Escuela Normal eran mantenidos como directores de escuela por lapsos prolongados, sin que se les ascendiera a cargos más altos. El artículo afirmaba que solo siete de los cincuenta y seis pedagogos graduados de la Normal entre 1906 y 1907 habían sido nombrados inspectores escolares. ${ }^{72}$ A pesar del interés de los normalistas, las autoridades nacionales no reclutaban un mayor número de ellos como inspectores.

Los normalistas se opusieron a la abolición de los inspectores escolares antes y después de que el Congreso adoptara esta medida. En junio de 1913, César Oré y Luque sostuvo que los maestros necesitaban contar con la supervisión, la guía y la protección especializadas de los inspectores. Oré creía que los inspectores anteriores habían sido meros agentes políticos. Alentó así al gobierno a que resolviera la cuestión, entregando las inspectorías a normalistas con experiencia como directores de centros escolares. ${ }^{73}$ A finales de febrero de 1914, un grupo de graduados de la Normal solicitó al gobierno nacional que no transfiriera las responsabilidades de los inspectores departamentales a los prefectos. El pedido afirmaba que estos últimos no tenían la formación necesaria para supervisar la educación. Había un mayor riesgo de que consideraciones políticas interfirieran en la instrucción primaria. El pedido insistía en solicitarle

\footnotetext{
${ }^{71}$ Luna 1911: 26-27.

72 «Por los normalistas» 1913: 1-3.

73 "Algo sobre los inspectores de instrucción» 1913: 11-12.
} 
al gobierno que nombrara inspectores a los graduados de la Normal. ${ }^{74}$ Luego de que José Pardo asumiera la presidencia por segunda vez, La Educación Nacional manifestó su confianza en el continuo apoyo que el presidente habría de prestar a la instrucción pública. La revista reconoció que, anteriormente, las inspecciones escolares habían sido otorgadas como favores políticos a fin de asegurar victorias electorales. La publicación alentó al ejecutivo a que reorganizara y restableciera las inspectorías, y que las entregara a graduados de la Escuela Normal. ${ }^{75}$

Hay evidencia de que los normalistas recurrieron ocasionalmente al clientelismo, a pesar de sus críticas públicas a este mecanismo. Tal vez no podía ser de otra manera, dada la omnipresencia del clientelismo en la cultura política peruana, el respaldo desigual que los educadores recibían del gobierno nacional, y su necesidad de promover sus intereses profesionales y de protegerse a sí mismos. Esto resultaba particularmente apremiante en la década de 1910, cuando el entorno político peruano era sumamente conflictivo. Los riesgos que los educadores enfrentaban quedan ejemplificados en el asesinato del maestro Florián Hurtado en 1918. Hurtado formaba parte de una familia acaudalada de Yanamarca y había seguido estudios universitarios en Lima. De vuelta en Junín, Hurtado fue nombrado director de la escuela pública del pueblo de Marco. La familia de Hurtado competía con los Onofre, otra familia prominente, por el control de la fuerza de trabajo local. La expansión de la industria minera en la región hizo que la mano de obra fuera un recurso cada vez más escaso a fines de la década de 1910. En agosto de 1918, los hermanos Antonio y Jacinto Onofre atacaron la escuela de Hurtado. Sus disparos ocasionaron la muerte al maestro y a uno de sus alumnos, e hirieron a la profesora local. Los Onofre jamás fueron juzgados por los asesinatos, pero la población de Marco se vengó de ellos destruyendo sus propiedades e impidiéndoles que regresaran al pueblo. ${ }^{76}$ Los educadores resultaban sumamente vulnerables en los conflictos locales.

\footnotetext{
${ }^{74}$ Encinas 1914: 11-16.

75 «Las inspecciones de instrucción primaria» 1916: 1-3.

${ }^{76}$ Mallon 1983: 214-219.
} 
Los graduados de la Normal debían enfrentar críticas a su labor docente, así como también ataques personales. José Antonio Encinas, quien inició su carrera docente como director de una escuela pública en Puno en 1907, rememoraba que el prefecto Manuel Ponce y el obispo Valentín Ampuero cuestionaban su labor. Ampuero discrepaba con el currículo y los métodos modernos que Encinas usaba, especialmente su supuesto rechazo a la educación religiosa. Encinas tenía el respaldo del Ministro de Instrucción, por lo que pudo continuar su trabajo a pesar de las críticas. ${ }^{77}$ En octubre de 1913, La Educación Nacional indicó que Francisco Campos, un normalista que trabajaba como director de la escuela pública de Cotahuasi había sido arrestado. El hijo de un juez local que estudiaba en la escuela de Campos había sufrido un accidente en la misma. Las autoridades locales acusaron a Campos de tentativa de homicidio y lo apresaron. La revista lo defendió argumentando que tal vez no cuidó de vigilar a sus alumnos, pero que no era posible acusarle de un crimen. La publicación sostuvo que era necesario proteger el prestigio personal de los maestros porque tenían una misión social noble. ${ }^{78}$

Contamos con al menos un caso aparente de participación de normalistas en redes de clientelismo. En noviembre de 1915, el diputado Rafael Grau se quejó ante su cámara de que el Ministro de Instrucción Wenceslao Valera planeaba cerrar una escuela particular en Canta por motivos exclusivamente políticos. Grau era opositor a la coalición gobernante conformada por los partidos Civil, Liberal, y Constitucional. El ministro, por su parte, era un prominente dirigente liberal. Según Grau, la escuela particular a que se refería era propiedad del normalista Cecilio A. Garrido, previamente despedido de la escuela pública local por razones meramente partidarias. Tras hacer esta denuncia, Grau solicitó que su cámara le pidiera explicaciones a Valera acerca del cese de varios educadores de las escuelas públicas de las provincias de la sierra de Lima. Grau añadió que el ministerio no estaba priorizando el nombramiento de graduados de la Normal, o de maestros diplomados, como lo requería

\footnotetext{
77 Encinas 1932.

78 «Protesta» 1913: 20.
} 
la ley. Algunos diputados cuestionaron las intenciones de Grau, afirmando que intentaba proteger a los maestros que lo habían apoyado en la última elección parlamentaria. Una vez hecha esta afirmación, Grau no volvió a quejarse, quizá aceptando tácitamente la validez del cargo que se le había hecho. ${ }^{79}$

El advenimiento del segundo mandato presidencial de Augusto Leguía en 1919 renovó las expectativas de muchos educadores públicos. Leguía llegó al poder con una retórica progresista que atrajo el apoyo de las clases medias urbanas y de los intelectuales indigenistas. El gobierno nacional nombró normalistas en puestos altos de la burocracia educativa y José Antonio Encinas, uno de ellos, llegó a ser parlamentario por el partido del presidente. Encinas se opuso a la reelección de Leguía en 1924, por lo que cayó en desgracia y tuvo que exiliarse. Retornó al Perú al caer Leguía en 1930, solo para volver a ser deportado en 1932. Fue en este contexto que Encinas cuestionó el proceso de centralización, al cual había estado cercano desde su inicio. Encinas sostenía que los gobiernos municipales habían llevado a cabo la mejor administración posible de las escuelas, no obstante carecer de los medios financieros o los conocimientos pedagógicos necesarios. Según él, la centralización fracasó porque la burocracia educativa carecía de la formación apropiada, porque el gobierno había favorecido a los clientes políticos por encima de los normalistas como inspectores escolares y porque los recursos financieros habían sido insuficientes. ${ }^{80} \mathrm{La}$ decepción de Encinas con la centralización se debió tanto a sus circunstancias personales, así como a las dificultades que el magisterio enfrentó en las primeras décadas del siglo XX.

\section{CONCLUSIONES}

La nueva generación de líderes del Partido Civil, encabezados por José Pardo, centralizaron la educación primaria en el Perú por motivos ideológicos y políticos. Factores económicos, institucionales, y sociales hicieron posible dicha reforma. Pardo y sus colaboradores querían

\footnotetext{
${ }^{79}$ Congreso de la República, Cámara de Diputados 1915: 348, 513.

${ }^{80}$ Encinas 1932: 70-74.
} 
expandir la instrucción primaria, y hacerla más efectiva, pero además buscaban fortalecer un Estado al que controlaban circunstancialmente, incrementando su dominio sobre recursos nacionales y locales, mejorando sus chances de recibir mayor apoyo y creando una comunidad nacional más abarcadora. Resulta revelador que el aspecto más contencioso de la centralización haya sido la creación de inspectores escolares que reportaban directamente al gobierno nacional. Los poderes regionales y locales resintieron a estos agentes estatales, que contaban no solo con prerrogativas educativas, sino también con influencia política y control sobre los recursos. Los inspectores podían intervenir en la política local y tomar decisiones sobre las plazas docentes y fondos escolares. La disponibilidad de recursos financieros fue crucial para el inicio de la centralización de la educación. Una vez que el gobierno nacional comenzó a tener problemas fiscales, la reforma fue cuestionada abiertamente. Sin embargo, hasta donde sabemos, congresistas y autoridades locales jamás pidieron el retorno al financiamiento descentralizado de las escuelas, muy posiblemente porque deseaban conservar el acceso a los fondos fiscales para sus propios fines políticos.

La disponibilidad de fondos fiscales contribuyó a hacer que la centralización fuera inicialmente viable, pero factores institucionales y sociales también fueron influyentes. El incremento de la cobertura educativa pública satisfizo las expectativas de una creciente clase media, que concebía la educación como un marcador de su identidad de clase, así como un vehículo potencial para la movilidad social y económica. ${ }^{81}$ Los maestros ya existentes, y los que aspiraban a serlo, podían esperar más empleos y una mayor estabilidad ocupacional dentro de un aparato educativo ampliado. Los educadores públicos, que vivían de su labor burocrática, tenían interés en el crecimiento continuo del gobierno nacional. Los requisitos fijados por el gobierno para ingresar a la Escuela Normal de Varones favorecían a estudiantes de las clases alta y media. Por su parte, los normalistas tuvieron la expectativa, satisfecha inicialmente, de gozar de buenas condiciones laborales; debido a su formación, padres,

${ }^{81} \mathrm{Al}$ respecto, ver Parker 1998. 
maestros, y funcionarios en general podían prever los beneficios de la centralización educativa.

En el corto plazo, las reformas del segundo civilismo introducidas en 1905 tuvieron varias consecuencias intencionales y no intencionales. La nueva generación del Segundo Civilismo intensificó inicialmente el ejercicio de su poder a nivel local a través de los inspectores escolares. Los poderes locales tradicionales se resistieron a la centralización administrativa de la educación y lograron abolir a dichos inspectores entre 1915 y 1920. El segundo civilismo reapareció temporalmente durante el segundo gobierno de Pardo, pero varios de sus integrantes fueron marginados de la política una vez que Leguía asumió el mando en 1919. El prestigio social de los educadores creció, especialmente en el caso de los graduados de la Escuela Normal, quienes contribuyeron a acentuar la renovación de ideas y prácticas pedagógicas, y a la consolidación de una nueva cultura magisterial. Los normalistas tuvieron un papel crucial en este proceso a través de la enseñanza, las publicaciones especializadas, y las conferencias pedagógicas. Sin embargo, la política partidaria siguió teniendo un efecto sobre la instrucción, con lo cual muchos educadores tuvieron que adaptarse a las circunstancias. Entre las consecuencias claramente positivas de la centralización, estuvo el incremento en el número de escuelas públicas, de alumnos y de docentes, especialmente maestras. En este sentido, la centralización tuvo un efecto integrador, pues una mayor cantidad de niños tuvo acceso a la educación y un mayor número de mujeres pudo acceder al empleo público.

\section{BIBLIOGRAFÍA}

«Algo sobre los inspectores de Instrucción». 1913. La Educación Nacional. Volumen 1, número 1: 11-12.

Aponte, Pedro L. 1911. «El maestro y la Patria». La Escuela Moderna. Volumen 1, número 2: 37-40.

Aponte, Pedro L. 1912. «La Patria, sus hombres notables y la escuela». La Escuela Moderna. Volumen 2, número 1: 9-14.

Aponte, Pedro L. 1913. «La dignidad del maestro». La Escuela Moderna. Volumen 1, número 4: 100-102.

Archer, Margaret. 2013. Social Origins of Educational Systems. Nueva York: Routledge. https://doi.org/10.4324/9780203584002 
Blanchard, Peter. 1982. The Origins of the Peruvian Labor Movement, 1883-1919. Pittsburgh: University of Pittsburgh Press.

Blanchard, Peter. 1997. "A Populist Precursor: Guillermo Billinghurst». Journal of Latin American Studies. Volumen 9, número 2: 251-273. https://doi. org/10.1017/S0022216X00020605

Basadre, Jorge. 1983. Historia de la República del Perú. Lima: Editorial Universitaria, 11 vols.

Bouroncle, Luis H. 1911. «La enseñanza de la historia y la educación cívica en la escuela primaria». La Escuela Moderna. Volumen 1, número 1: 104-105.

Castro, Enrique. 1912. Legislación municipal. Recopilación de leyes, decretos, resoluciones, acuerdos, reglamentos, ordenanzas, tarifas, etc., relativos a la administración comunal. Lima: Librería Francesa Científica E. Rosay.

Ccahuana Córdova, Jorge Alberto. 2014. «¿Educar al indígena? El Partido Civil y los jóvenes reformistas a inicios de la República Aristocrática». Histórica. Volumen 38, número 1: 85-127

Ccahuana Córdova, Jorge Alberto. 2020. «La reforma educativa de 1905: Estado, indígenas y políticas racializadas en la República Aristocrática». Apuntes. Número 86: 5-32. https://doi.org/10.21678/apuntes.86.880

Congreso de la República. 1912. Legislaturas ordinaria y extraordinaria de 1911 y 1912, Congreso. Desde el 28 de julio al 14 de marzo de 1912. Lima: Imprenta de «El Diario».

Congreso de la República. 1915. Legislatura ordinaria de 1915. Lima: Tipografía de «La Prensa».

Congreso de la República. 1917. Legislatura ordinaria y extraordinaria de 1917. Tipografía de «La Prensa».

Congreso de la República. 1919. Legislaturas ordinaria y extraordinaria de 1918. Lima: Tipografía de «La Prensa».

Congreso de la República, Cámara de Diputados. 1904. $2^{\circ}$ Congreso extraordinario, 1904. Desde 10 de diciembre de 1904 al 23 de enero de 1905. Lima: Imprenta de «El Comercio».

Congreso de la República, Cámara Diputados. 1910. Cámara de diputados, 1a, $2^{a}$ y $3^{a}$ legislaturas extraordinarias, 1909. 28 de octubre de 1909 al 12 de marzo de 1910. Lima: Imprenta de «El Comercio».

Congreso de la República, Cámara de Diputados. 1914. Cámara de Diputados. Ordinario 1914. Desde el 13 de julio al $1^{\circ}$ de octubre. Lima: Gil.

Congreso de la República, Cámara Diputados. 1912. Diputados. $1^{\circ}$ y $2^{\circ}$ congresos extraordinarios 1912. Desde el 28 de octubre al 23 de diciembre. Lima: Tipografía de «La Prensa».

Congreso de la República, Cámara de Diputados. 1913. Diputados. Congreso ordinario 1913. Desde el 13 de julio al 25 de octubre. Lima: Tipografía "La Prensa». 
Congreso de la República, Cámara de Diputados. 1914. Diputados. $1^{\circ}$ congreso extraordinario 1914. Desde el 29 de octubre al 12 de diciembre. Lima: Gil.

Congreso de la República, Cámara de Diputados. 1915. Diputados. 1 a legislatura extraordinaria 1915. Desde el 27 de octubre al 10 de diciembre. Lima: Tipografía de «La Prensa».

Congreso de la República, Cámara de Diputados. 1917. Diputados, legislatura ordinaria 1917. Desde el 13 de julio al 25 de octubre. Lima: Tipografía de «La Prensa».

Congreso de la República, Cámara de Senadores. 1905. Congreso ordinario, 1905. Desde 13 de julio al 25 de octubre de 1905. Lima: Imprenta de «El Comercio». Congreso de la República, Cámara de Senadores. 1909. Congreso ordinario de 1909. Senadores. Desde el 13 de julio al 25 de octubre. Lima: Imprenta de «El Diario». Congreso de la República, Cámara de Senadores. 1911. Cámara de senadores, congreso ordinario, 1911. Desde el 13 de julio de 1911 al 25 de octubre. Lima: Imprenta de «El Lucero».

Congreso Pedagógico Regional. 1912. Primer Congreso Pedagógico Regional del Norte. Actas de sesiones, tesis, informes y conclusiones aprobadas. Trujillo: Imprenta Jacobs.

Congreso Regional de Normalistas. 1911. Informes y Conclusiones del Primer Congreso Regional de Normalistas reunido en Arequipa en enero de 1911. Arequipa: Tip. La Bolsa.

Contreras, Carlos. 1996. Maestros, mistis y campesinos en el Perú rural del siglo XX. Lima: Instituto de Estudios Peruanos.

Dancuart, Pedro Emilio. 1903-1926. Anales de la hacienda pública del Perú; historia $y$ legislación fiscal de la república. Lima: Imprenta, 24 volúmenes.

Dewey, John. 1913a. «Las ideas pedagógicas de John Dewey», La Escuela Moderna. Volumen III, número 5: 145-148.

Dewey, John. 1913b. "Las ideas pedagógicas de John Dewey", La Escuela Moderna. Volumen III, número 6: 186-189.

Dewey, John. 1913c. "El credo pedagógico de John Dewey", La Escuela Moderna. Volumen III, número 7: 230-232.

Dewey, John. 1913d. "Las ideas pedagógicas de John Dewey", La Escuela Moderna. Volumen III, número 8: 279-282.

Dewey, John. 1914a. "La escuela y la vida del nińo", La Escuela Moderna. Volumen IV, número 7: 212-218.

Dewey, John. 1914b. "La escuela y la vida del nińo", La Escuela Moderna. Volumen IV, número 8: 243-250.

Dirección de Salubridad Pública. 1915. Censo de la provincia de Lima (26 de junio de 1908). Lima: La Opinión Nacional.

Eastwood, Jonathan. "Positivism and Nationalism in $19^{\text {th }}$ Century France and Mexico". Journal of Historical Sociology. Volumen 17, número 4: 331-357. https://doi.org/10.1111/j.1467-6443.2004.00236.x 
«El parlamento y la instrucción pública». 1913. La Educación Nacional. Volumen 1, número 2: 1-10.

Encinas, José Antonio. 1912a. «Psicología infantil. Método de observación». La Escuela Moderna. Volumen 2, número 1: 1-9.

Encinas, José Antonio. 1912b. «La psicología experimental». La Escuela Moderna. Volumen 2, número 4: 119-121.

Encinas, José Antonio. 1914. «Memorial de los normalistas pidiendo la conservación de las inspecciones de instrucción. Este memorial fue redactado por José A. Encinas». La Educación Nacional. Volumen 2, número 7: 11-16.

Encinas, José Antonio. 1932. Un ensayo de escuela nueva en el Perú. Lima: Imp. Minerva.

Espinoza, G. Antonio. 2013. Education and the State in Modern Peru. Primary Schooling in Lima, 1821-c.1921. New York: Palgrave Macmillan. https://doi. org/10.1057/9781137333032

Espinoza, G. Antonio. 2016. "Civilizadores del pueblo": Maestros Primarios y Estado en Lima, 1860 - ca.1905». Caravelle. Cahiers du monde hispanique et luso-brésilien. Número 106: 61-78. https://doi.org/10.4000/caravelle.1938

García-Liendo, Javier. 2017. «Teachers, Folklore, and the Crafting of Serrano Cultural Identity in Peru». Latin American Research Review. Volumen 52, número 3: 378-392. https://doi.org/10.25222/larr.78

Garmendia, Roberto F. 1914. «Observaciones psicológicas». La Escuela Moderna. Volumen 4, número 7: 223-227.

González de Fanning, Teresa. 1892. «Trabajo para la mujer». En Gorriti, Juana Manuela (ed.). Veladas literarias de Lima, 1876-1877. Buenos Aires: Imprenta Europea, 286-293.

Infante, Luis C. 1914a. «Al iniciarse la jornada...». La Escuela Moderna. Volumen 4, número 1: 11-14.

Infante, Luis C. 1914b. «El estudio del niño». La Escuela Moderna. Volumen 4, número 5: 137-142.

James, William. 1914. Talks to Teachers on Psychology: And to Students on Some of Life's Ideals. Nueva York: Henry Holt and Company.

Katz, Michael B. 1987. Reconstructing American Education. Cambridge y Londres: Harvard University Press.

«Las inspecciones de instrucción primaria». 1916. La Educación Nacional. Volumen 3, número 10: 1-10.Ley orgánica de enseñanza. 1920. Lima: Imp. Americana.

Luna, Humberto. 1911. Cuestiones educativas. Cuzco: Tipografía Americana.

Luna, Humberto. 1913. Paidología (el niño del Cuzco). Tesis para el Bachillerato en la Facultad de Ciencias Naturales de la Universidad San Antonio Abad del Cuzco. Cuzco: Imprenta de «El Trabajo».

MacKnight, J. A. 1911 a. «El propósito de La Escuela Moderna». La Escuela Moderna. Volumen 1, número 1: 1. 
MacKnight, J. A. 1911b. «iMaestros, adelante!». La Escuela Moderna. Volumen 1, número 2: 35-36.

MacKnight, J. A. 1913. «Cuatro palabras con los maestros». La Escuela Moderna. Volumen 3, número 2: 43-44.

MacKnight, J. A. 1914. «Consultas pedagógicas». La Escuela Moderna. Volumen 4, número 6: 201-202.

MacKnight, J. A. y Héctor Chávez Ratto. 1915. «Los “tests” de Binet y Simón». La Escuela Moderna. Volumen 5, número 2: 34-38.

MacKnight, J. A. 1916. Caracteres físicos y mentales del niño peruano. Lima: Imprenta de E. Z. Casanova.

Mallon, Florencia. 1983. The Defense of Community in Peru's Central Highlands. Peasant Struggle and Capitalist Transition, 1860-1940. Princeton: Princeton University Press. https://doi.org/10.1515/9781400856046

Martín, José Carlos. 1996. «Instrucción Pública (1904-1908)». Boletín del Instituto Riva-Agüero. Número 23: 413-426.

«Memorial». 1913. La Educación Nacional. Volumen 1, número 4: 17-20.

Merino Reyna, Amador. 1913. «La escala de sueldos de los preceptores». La Educación Nacional. Volumen 1, número 3: 6-8.

Miller, Rory. 1982. «The Coastal Elite and Peruvian Politics, 1895-1919». Journal of Latin American Studies. Volumen 14, número 1: 97-120. https://doi. org/10.1017/S0022216X0000359X

Ministerio de Fomento. Dirección de Estadística. 1918. Extracto estadístico, correspondiente al año 1918. Lima: Imp. Americana, 1919.

Ministerio de Hacienda y Comercio. 1906. Presupuesto General para... Lima: Torres Aguirre.

Ministerio de Hacienda y Comercio. 1907. Presupuesto General y Presupuestos Departamentales para... Lima: Gil.

Ministerio de Hacienda y Comercio. 1908. Presupuesto General y Presupuestos Departamentales para ... Lima: Torres Aguirre.

Ministerio de Hacienda y Comercio. 1909. Presupuesto General y Presupuestos Departamentales para... Lima: s.i.

Ministerio de Hacienda y Comercio. 1910. Presupuesto General para... Lima: Oficina Tipográfica de «La Opinión Nacional».

Ministerio de Hacienda y Comercio. 1912. Presupuesto General para... Lima: Escuela Nacional de Artes y Oficios.

Ministerio de Hacienda y Comercio. 1913. Presupuesto General para... Lima: La Opinión Nacional.

Ministerio de Hacienda y Comercio. 1914. Presupuesto General para... Lima: La Penitenciaría.

Ministerio de Hacienda y Comercio. 1918. Presupuesto General para... 1918. Lima: Imprenta Americana. 
Ministerio de Hacienda y Comercio. 1919. Presupuesto General para 1919. Lima: Americana.

Ministerio de Hacienda y Comercio. 1920. Presupuesto General para... Lima: Imprenta «La Opinión Nacional».

Ministerio de Instrucción Pública. 1907. Plan de Estudios y Reglamento Interior de la Escuela Normal de Varones. Lima: Imp. Nacional.

Ministerio de Instrucción, Justicia, Culto y Beneficencia. 1876. Memoria que al Congreso Nacional de 1876 presenta el Ministro de... Lima: Empresa Tipográfica.

Ministerio de Justicia, Culto, Instrucción y Beneficencia. 1890. Estadística escolar de la república... Anexo a la Memoria del Ministerio de Justicia, Culto, Instrucción y Beneficencia. Lima: Torres Aguirre.

Ministerio de Justicia, Instrucción y Culto. 1907. Memoria presentada por el Ministro de...al Congreso Ordinario de 1907. Lima: Torres Aguirre.

Ministerio de Justicia, Instrucción y Culto. 1908. Memoria presentada por el Ministro de...al Congreso Ordinario de 1908. Lima: Imp. Torres Aguirre, 3 volúmenes.

Ministerio de Justicia, Culto, Instrucción y Beneficencia. 1910. Memoria presentada por el Ministro de... al Congreso Ordinario de 1910. Lima: Tipografía «La Revista", 2 volúmenes.

Ministerio de Justicia. Instrucción, Culto y Beneficencia. 1917. Memoria que el Ministro de justicia, instrucción, culto y beneficencia... presenta al Congreso ordinario de 1917. Lima: Oficina Tip. de «La Opinión Nacional», 3 volúmenes.

Ministerio de Justicia, Culto, Instrucción y Beneficencia. 1919. Memoria que el Ministro de Justicia, Instrucción, Culto y Beneficencia... presenta al Congreso Ordinario de 1919. Lima: Torres Aguirre.

Ministerio de Justicia, Culto, Instrucción y Beneficencia. 1920. Memoria que presenta el Ministro de Justicia, Instrucción, Culto y Beneficencia...al Congreso Ordinario de 1920. Lima: Torres Aguirre.

Ministerio de Justicia, Culto, Instrucción y Beneficencia. 1922. Memoria que el Ministro de... presenta al Congreso Ordinario de 1922. Lima: Imprenta Americana.

Ministerio de Instrucción. Dirección General de Enseńanza. 1928. Extracto de la Estadística Escolar de 1926. Lima: La Opinión Nacional.

Newland, Carlos. "The Estado Docente and Its Expansion: Spanish American Elementary Education, 1900-1950». Journal of Latin American Studies. Volumen 26, número 2: 449-467. https://doi.org/10.1017/S0022216X00016291

Parker, David S. 1998. The Idea of the Middle Class. White-Collar Workers and Peruvian Society, 1900-1950. University Park: Penn State University Press.

Poiry, Isidoro. 1905. «Fiesta Inaugural. Discurso del Director de la Escuela». En Ministerio de Instrucción Pública. Escuela Normal de Varones 1905. Lima: s.i, 5-11.

Polar, Jorge. 1906. «Discurso pronunciado ante la Honorable Cámara de Senadores, por el Señor Ministro de Instrucción..., 20 de setiembre de 1905». En Ministerio de Instrucción Pública. Reformas de la Primera Enseñanza. Lima: E. Rosay, 3-11. 
Polar, Jorge. 1900. «La patria es una realidad natural, moral y jurídica. Tesis presentada por el seńor Jorge Polar al optar el grado de Bachiller en la Facultad de Ciencias Políticas y Administrativas». Anales de la Universidad Mayor de San Marcos de Lima. Volumen 27: 173-182.

«Por los normalistas». 1913. La Educación Nacional. Volumen 1, número 3: 1-3. Prialé, Ángel Alfredo. 1913a. «La educación primaria en el Perú, desde 1905 hasta 1913». La Educación Nacional. Volumen 1, número 1: 6-8.

Prialé, Ángel Alfredo. 1918. «La nivelación de los haberes de los preceptores». La Educación Nacional. Volumen 4, número 11: 6-13.

«Protesta». 1913. La Educación Nacional. Volumen 1, número 5: 20.

Reglamento general de instrucción primaria. 1922. Lima: Litografía e Imprenta T. Scheuch.

Ugarte, José B. 1911. "Moral cívica». La Escuela Moderna. Volumen 1, número 8: 245-247.

Villarán, Manuel Vicente. 1914. «La instrucción primaria en el Perú de 1873 a 1901», Revista Universitaria. Año 9, volumen 2: 201-223.

Villarán, Manuel Vicente. 1913. «La instrucción primaria en el Perú de 1850 a 1873", Revista Universitaria. Año 8, volumen 2: 547-561.

Villarán, Manuel Vicente. 1913. «La instrucción primaria de 1821 a 1850». Revista Universitaria. Año 8, volumen 1: 313-323.

Fecha de recepción: 22/II/2021

Fecha de aceptación: 29/IV/2021 